\title{
Association of Severity of Allergic Conjunctivitis with Skin Prick Test
}

\author{
Amena Masrur, Muhammad Adnan, Furqan Ahmed Khan and Ali Tayyab \\ Department of Ophthalmology, Islamabad Medical and Dental College, Islamabad, Pakistan
}

\begin{abstract}
Objective: To investigate the association between skin prick test and severity of allergic conjunctivitis.

Study Design: Cross sectional observational study.

Study Place and Duration of Study: Akbar Niazi Teaching Hospital, Bara Kahu, Islamabad, between March and September 2019.

Methodology: 150 eyes of 150 diagnosed cases of allergic conjunctivitis, who had had a skin prick test, were included in the study. Cases with other concurrent ocular surface diseases, conjunctivitides, systemic allergies, and those on systemic steroids, anti-histamines and tricyclic antidepressant agents were excluded. Signs of allergic conjunctivitis were graded via slit-lamp examination using a 5-5-5 exacerbation grading scale. Allergic conjunctivitis was classified as being severe if the total score was $\geq 230$, moderate if the score was $>20$ and $<230$, and mild if the score was $\leq 20$. Frequency distribution was reported for age, gender and result of skin prick test. Test of significance and correlation analysis was carried out between the result of skin prick test and the severity of allergic conjunctivitis using Statistical Package for Social Sciences version 20.0. A p-value of $<0.05$ was taken as significant.

Results: Mean age was $18.62( \pm 8.15)$ years in 91 males and 59 females. Mild $(n=28)$, moderate $(n=77)$, and severe $(n=45)$ cases showed no statistically significant correlation with the skin prick test (positive or negative) in any of the three categories (mild $p=0.44, r=0.153$, moderate $p=0.89, r=0.016$, and severe $p=0.73, r=0.052$ ).
\end{abstract}

Conclusion: Skin prick test did not show a significant association or correlation with the severity of allergic conjunctivitis.

Key Words: Allergic conjunctivitis, Hypersensitivity, Skin prick test.

How to cite this article: Masrur A, Adnan M, Khan FA, Tayyab A. Association of Severity of Allergic Conjunctivitis with Skin Prick Test. J Coll Physicians Surg Pak 2020; 30(11):1166-1169.

\section{INTRODUCTION}

Ocular allergic conjunctivitis is a set of inflammatory diseases that usually manifest at a young age; in most patients is secondary to type 1 hypersensitivity reactions. ${ }^{1}$ It is broadly classified as acute and chronic; with the acute variant being limited to or exacerbating in specific season(s) and the chronic type persisting all year round. ${ }^{2}$ Climatic, genetic and environmental factors determine the severity of symptoms experienced by the patient. ${ }^{3}$ It is estimated that allergic conjunctivitis affects $5-22 \%$ of the human population; the exact prevalence varies with both the geographic region and location. ${ }^{4}$ In Pakistan, a prevalence of $19 \%$ has been reported. ${ }^{5}$

Correspondence to: Dr. Ali Tayyab, Department of Ophthalmology, Islamabad Medical and Dental College, Islamabad, Pakistan

E-mail: ali.tayyab@gmail.com

Received: August 25, 2020; Revised: October 20, 2020;

Accepted: October 28, 2020

DOI: https://doi.org/10.29271/jcpsp.2020.11.1166
An extensive inquiry into the etiology of allergic conjunctivitis is generally overlooked, resulting in the disease being underdiagnosed and undertreated. ${ }^{1}$ This increases the likelihood of the development of complications associated with ocular allergies; these include increasing corneal astigmatism, keratoconus and cornealulcers. ${ }^{6}$

To ensure timely diagnosis and management of ocular allergic reactions, the utility of the skin prick test has been explored with varying results, with some researchers supporting, ${ }^{7-9}$ while others finding no significant relationship between the two. ${ }^{10}$ Though investigations into the prevalence of allergic conjunctivitis have been reported from Pakistan; to the best of authors' knowledge, this is the first investigation of its kind. Its aim was to investigate the relationship between the severity of allergic conjunctivitis (using a 5-5-5-grading scale) and the skin prick test.

\section{METHODOLOGY}

Approval for this cross-sectional observational study was obtained from the Institutional Review Board (IRB) of the Hospital. A total of 150 cases (150 eyes) were recruited for the study from the Outpatient Department of Akbar Niazi Teaching Hospital between March and September 2019 through purpo- 
sive sampling. Diagnosed patients of allergic conjunctivitis of either gender, who were between the ages of 10 and 60 years and had already undergone a skin prick test, were included in the study. Patients with concurrent ocular surface diseases, infectious as well as non-allergic non-infectious conjunctivitides were excluded from the study. Cases with concurrent systemic allergies were also excluded from the study. Patients on systemic steroids, systemic anti-histamines, and tricyclic antidepressant drugs were also excluded from the study since the use of these agents may interfere with cutaneous hypersensitivity reactions.

A full disclosure of the study objectives and methods was made to the cases, and informed consents were taken. In the case of patients under 18 years of age, the consent was obtained from the parents or legal guardians. All the cases were made familiar with the procedure of examination by demonstration. After a detailed history, the cases underwent a complete ocular examination. The patients were evaluated for signs of allergic conjunctivitis using a slit lamp biomicroscope by a single observer with a major postgraduate degree and 7 years postgraduate experience, who was blind to the study. The signs were graded using a standardised 5-5-5 exacerbation grading scale (Table I). This grading methodology takes into account 5 clinical signs in each of the 100-point, 10-point, and 1-point categories. Each sign that was positive in a particular category was multiplied by its designated points. The theoretical maximum total attainable score was 555; while the minimum attainable score was 0. Greater weightage was assigned to signs in the 100-point category as their presence was indicative of more severe disease. Similarly, the weightage assigned to the signs in the 5-point and 1-point categories were representative of the presence of the signs in relatively milder allergic conjunctival disease. The scores in each category were added to calculate the severity score for each individual patient. The signs included in the 100-point category were the presence of active giant papillae, gelatinous limbal infiltration, exfoliative epithelial keratopathy, shield ulceration and the proliferation of papillae on the lower palpebral conjunctiva. The 10-point category included the following signs; blepharitis, velvety appearance of papillae, Horner-Tranta's spots, edema of the bulbar conjunctiva, and superficial punctate keratopathy. Finally, the signs in the 1point category included the presence of papillae in the upper palpebral conjunctiva, follicles in the lower palpebral conjunctiva, hyperemia of the palpebral conjunctiva and lacrimal effusion. The allergic conjunctivitis was graded as being severe if the total score was more than or equal to 230 , moderate if the score was more than 20 but less than 230 , and mild if the score was equal to or less than 20.

The age, gender, score from the clinical examination of the patient using the 5-5-5 exacerbation grading scale (referred to a 5-5-5- grading scale) as well as the result of the skin prick test was entered into the database. Categorical variables were expressed as frequency and percentage, while quantitative variables as mean $( \pm S D)$. Independent sample t-test was applied to compare mean total scores with the result of the skin prick test. The result of the skin prick test was correlated against mean disease severity scores using Pearson's correlation. In all cases a $p$-value of less than 0.05 was taken as significant. IBM SPSS Statistics version 20 was used to perform all data analyses.

\section{RESULTS}

A total of 150 eyes of 150 cases were enrolled in the study, of which $60.7 \%(n=91)$ were males and $39.3 \%(n=59)$ were females. The mean age of the patients was $18.62( \pm 8.15)$ years. The skin prick test was positive in $38.7 \%(n=58)$, and negative in $61.3 \%(n=92)$ of cases.

Based on the 5-5-5-grading scale, a total of $18.7 \%(n=28)$ cases had the mild form of allergic conjunctivitis, $51.3 \%(n=77)$ had the moderate form, while $30 \%(n=45)$ suffered from the severe variety. The mean score of these categories based on the result of their skin prick test is shown in Tablell.

There was no statistically significant difference in the mean score of the patients with mild $(p=0.44)$, moderate $(p=0.89)$ or severe allergic conjunctivitis $(p=0.73)$ with a positive or negative skin prick test (Table II). A very slight positive but statistically insignificant correlation was seen between the mild ( $r=$ $0.153)$ moderate $(r=0.016)$ and severe $(r=0.052)$ forms of allergic conjunctivitis with the results of the skin prick test.

\section{DISCUSSION}

The objective of this study was to ascertain the correlation between the skin prick test and the severity of allergic conjunctivitis based on the 5-5-5 grading scale. To the authors' knowledge, this is the only study from Pakistan that addresses this aspect using the 5-5-5 grading scale. The 5-5-5 grading scale utilises commonly, seen clinical signs, ${ }^{11,12}$ is easy to use, and is recommended to be employed to grade the severity of allergic conjunctival disease. ${ }^{11}$ Establishing a relation between the skin prick test and the severity of allergic conjunctivitis may allow the use of the former to form a predictor for the nature of allergic conjunctivitis in terms of the severity of the disease.

In each of the three categories of allergic conjunctivitis (mild, moderate, and severe), the mean score on the 5-5-5 grading scale was greater for patients with a positive skin prick test as compared to those with a negative one (Table II). However, this was not statistically significant (Table II). In each of the three groups, there were more patients with a negative skin prick test as compared to those in whom it was positive (Table II). It has been suggested that the skin prick test might be a confirmatory test for allergic conjunctivitis since it is an $\lg E$ mediated hypersensitivity reaction. ${ }^{9}$

The present findings are similar to those of an investigation on Brazilian population. ${ }^{13}$ Both the countries show a high prevalence of allergic conjunctival disease; with Pakistan reporting a prevalence of $19 \%,{ }^{5}$ while the data from Brazil showing a prevalence of $15-20 \%{ }^{14}$ 
Table I: The 5-5-5 exacerbation grading scale.

\begin{tabular}{|c|c|}
\hline Grade & Signs \\
\hline \multirow{5}{*}{$\begin{array}{l}\text { 100-point } \\
\text { Score: } 100 \times \text { Number of positive signs } \\
\text { Min score: } 0 \\
\text { Max score: } 500\end{array}$} & 1. Active giant papillae \\
\hline & 2. Gelatinous infiltrates of limbus \\
\hline & 3. Exfoliative epithelial keratopathy \\
\hline & 4. Shield ulcer \\
\hline & 5. Papillary proliferation at lower palpebral conjunctiva \\
\hline \multirow{5}{*}{$\begin{array}{l}\text { 10-Point } \\
\text { Score: } 10 \times \text { Number of positive signs } \\
\text { Min score: } 0 \\
\text { Max score: } 50\end{array}$} & 1. Blepharitis \\
\hline & 2. Papillary proliferation with velvety appearance \\
\hline & 3. Horner's Tranta's spots \\
\hline & 4. Edema of bulbar conjunctiva \\
\hline & 5. Superficial punctate keratopathy \\
\hline \multirow{4}{*}{$\begin{array}{l}\text { 1-Point } \\
\text { Score: } 1 \text { x Number of positive signs } \\
\text { Min score: } 0 \\
\text { Max score: } 5\end{array}$} & 1. Papillae at upper palpebral conjunctiva \\
\hline & 2. Follicles at lower palpebral conjunctiva \\
\hline & 3. Hyperemia of palpebral conjunctiva \\
\hline & $\begin{array}{l}\text { 4. Hyperemia of bulbar conjunctiva } \\
\text { 5. Lacrimal effusion }\end{array}$ \\
\hline Total score & $\begin{array}{l}\text { (100 } \times \text { Number of positive signs in 100-point grade })+(10 \times \text { Number of positive signs in 10-point } \\
\text { grade })+(1 \times \text { Number of positive sings in } 1 \text {-point grade })\end{array}$ \\
\hline
\end{tabular}

Table II: Number of cases of positive and negative skin prick test their respective 5-5-5 exacerbation grading scale mean score, p-value and correlation.

\begin{tabular}{|c|c|c|c|c|c|c|}
\hline \multirow{2}{*}{$\begin{array}{l}\text { Severity of allergic } \\
\text { conjunctivitis }\end{array}$} & \multicolumn{2}{|c|}{ Number of cases $(n)$} & \multicolumn{2}{|c|}{ Mean score \pm SD } & \multirow[b]{2}{*}{ p-value } & \multirow{2}{*}{$\underset{r}{\text { Correlation }}$} \\
\hline & $\begin{array}{c}\text { Positive skin prick } \\
\text { test }\end{array}$ & $\begin{array}{c}\text { Negative skin prick } \\
\text { test }\end{array}$ & Positive skin prick test & $\begin{array}{c}\text { Negative skin prick } \\
\text { test }\end{array}$ & & \\
\hline Mild & 11 & 17 & $10.18 \pm 5.12$ & $8.65 \pm 4.95$ & 0.44 & 0.153 \\
\hline Moderate & 26 & 51 & $99.08 \pm 64.08$ & $96.86 \pm 65.64$ & 0.89 & 0.016 \\
\hline Severe & 21 & 24 & $341.81 \pm 106.16$ & $331.29 \pm 99.03$ & 0.73 & 0.052 \\
\hline
\end{tabular}

The investigation carried out by them revealed no statistically significant correlation between the severity of allergic conjunctivitis and the cutaneous hypersensitivity reaction as assessed by the skin prick test. The age group of the patients in both the studies was also comparable (with a majority of the patients being in the pediatric age group). In both the studies, there were more male than female patients; this may be a manifestation of a male predilection shown by chronic allergic conjunctival disease.

Investigations carried out on the Chinese population, however, revealed a significant positive correlation between the severity of allergic conjunctivitis and the skin prick test. ${ }^{7}$ However, their sample size was considerably smaller than ours ( $n=40$ as opposed to $\mathrm{n}=150$ for our investigation).

The skin prick test was found to be positive in all the tested patients ( $n=38$ ), who presented with ocular allergies in a limited study done on the Lebanese population. ${ }^{15}$ This is in contrast to this study where the number of patients with a negative skin prick test $(n=92)$ outnumbered those with a positive test $(n=58)$. A difference in the sample size of the two studies may have been responsible for this difference in the results obtained for the two populations.

A study of a comparative size $(n=144)$, reported that the skin prick test is not a good predictor for ocular allergic conjunctivitis and can be deceptive as it may falsely identify an allergen that exhibits systemic hypersensitivity, while the conjunctival tissue is not sensitive to it. ${ }^{16}$

Another investigation surmised that around $50 \%$ patients of ocular allergic conjunctivitis exhibit a negative skin prick test. ${ }^{17}$ This finding is similar to that of our study where $61.30 \%$ of the cases showed a negative skin prick test. It must be noted however, that the utility of the skin prick test has been demonstrated to be higher in the diagnosis of IgE mediated allergic reactions such as allergic rhinitis and dermatitis. ${ }^{18}$ Allergic conjunctivitis seems to be an exception to this rule, a fact that may be attributed to a deviation of the Th2 lymphocyte line involved in pathogenesis of conjunctival allergic reactions. ${ }^{17}$ The study of conjunctival scrapings to look for evidence of inflammatory mediators released in response to an allergy have been shown to be unreliable as well. ${ }^{19}$ However, when allergic conjunctivitis is accompanied by other IgE mediated allergies, a positive skin prick test is reported to be present in a higher percentage of the study population. ${ }^{20}$

From the analysis of the present data and its corroboration with the findings of other studies, a mixed result has been obtained. There is a lack of conclusive evidence that may be used to either support or refute the utility of the skin prick test in the diagnosis of ocular allergic conjunctivitis. However, majority of these studies imply that the skin prick test poorly correlates with the severity of allergic conjunctivitis. ${ }^{13,16,17}$ Thus, it is unlikely to have high utility in the identification of patients, who may suffer from more severe forms of the disease. Furthermore, it can also be stated with confidence that since the severity of allergic conjunctivitis shows poor correlation to the tested allergens, therapy against these specific allergens may prove to be of little benefit for the patients as far as ocular symptoms are concerned.

The limitations of this study include a non-random selection of patients, lack of controls and a limited selection of tested allergens. A randomised controled trial with an extensive array of allergens used for the skin prick test may be 
performed to further corroborate the findings of this study in the local population.

\section{CONCLUSION}

No statistically significant relationship exists between the severity of allergic conjunctivitis and the results of the skin prick test. A weak, positive correlation was observed between the severity of allergic conjunctivitis and the result of the skin prick test that was not statistically significant.

\section{ETHICAL APPROVAL:}

Approval for this cross-sectional observational study was obtained from the Institutional Review Board (IRB) of the Hospital.

\section{PATIENTS' CONSENT:}

Informed consents were taken from patients. In the case of patients under 18 years of age, the consent was obtained from the parents or legal guardians.

\section{CONFLICT OF INTEREST:}

The authors declared no conflict of interest.

\section{AUTHORS' CONTRIBUTION:}

AM: Study concept, design, research proposal for Ethics Committee review, data maintenance and first draft critical review.

MA: Data acquisition, cross checking and finalisation of reference and statistics.

FAK: Study design and compilation of results.

AT: Study design, maintaining the database for this study, statistical analysis and interpretation of results.

\section{REFERENCES}

1. Friedlaender MH. Conjunctivitis of allergic origin: Clinical presentation and differential diagnosis. Surv Ophthalmol 1993; 38:105-14. doi: 10.1016/0039-6257(93)90035-6.

2. Fauquert JL. Diagnosing and managing allergic conjunctivitis in childhood: The allergist's perspective. Pediatr Allergy Immunol 2019; 30(4):405-414. doi: 10. 1111/pai.13035.

3. Patel DS, Arunakirinathan M, Stuart A, Angunawela R. Allergic eye disease. BMJ 2017; 359:j4706. doi: 10.1136/ bmj.j4706.

4. Leonardi A, Castegnaro A, Valerio AL, Lazzarini D. Epidemiology of allergic conjunctivitis: Clinical appearance and treatment patterns in a population-based study. Curr Opin Allergy Clin Immunol 2015; 15(5):482-8. doi: 10.1097/ ACI.00000 00000000204.

5. Baig R, Ali AW, Ali T, Ali A, Shah MN, Sarfaraz A, et al. Prevalence of allergic conjunctivitis in school children of Karachi. J Pak Med Assoc 2010; 60(5):371-3.

6. Arif AS, Aaqil B, Siddiqui A, Nazneen Z, Farooq U. Corneal complications and visual impairment in vernal keratoconjunc- tivitis patients. J Ayub Med Coll 2017; 29(1): 58-60.

7. Yang $S$, Jiang $Y$, Jin YM, Zhang JY, Li Y. Characteristics of allergic conjunctivitis with positive skin prick test. Chin J Ophthalmol 2017; 53(9):689-93. doi: 10.3760/cma.j.issn. 0412-4081.2017.09.010.

8. Almaliotis D, Michailopoulos P, Gioulekas D, Giouleka P, Papakosta D, Siempis T, et al. Allergic conjunctivitis and the most common allergens in Northern Greece. World Allergy Organ J 2013; 6(1):12. doi: 10.1186/1939-4551-6-12.

9. Leonardi A, Bogacka E, Fauquert JL, Kowalski ML, Groblewska A, Jedrzejczak-Czechowicz M, et al. Ocular allergy: Recognizing and diagnosing hypersensitivity disorders of the ocular surface. Allergy 2012; 67(11): 1327-37. doi: 10.1111/alI.12009.

10. Bonini S, Sacchetti M, Mantelli F, Lambiase A. Clinical grading of vernal keratoconjunctivitis. Curr Opin Allergy Clin Immunol 2007; 7(5):436-41. doi: 10.1097/ACl. 0b013e3282efb726.

11. Shoji J, Inada N, Sawa M. Evaluation of novel scoring system named 5-5-5 exacerbation grading scale for allergic conjunctivitis disease. Allergol Int 2009; 58(4):591-7. doi: 10.2332/allergolint.09-OA-0100.

12. Zicari AM, Capata G, Nebbioso M, De Castro G, Midulla F, Leonardi L, et al. Vernal Keratoconjunctivitis: An update focused on clinical grading system. Ital J Pediatr 2019; 45(1):64. doi: 10.1186/s13052-019-0656-4.

13. Augusto de Oliveira L, Mallozi MC, Sole D, Freitas D, Sousa LB, Mannis MJ. Are cutaneous hypersensitivity tests to inhalant allergens a severity marker for vernal keratoconjunctivitis? Arq Bras Oftalmol 2007; 70(6):991-5. doi: 10.1590/ s0004-27492007000600020.

14. Rosario N, Bielory L. Epidemiology of allergic conjunctivitis. Curr Opin Allergy Clin Immunol 2011; 11(5):471-6. Doi: 10.1097/ACl.0b013e32834a9676.

15. Arej N, Irani C, Abdelmassih Y, Slim E, Antoun J, Bejjani R, et al. Evaluation of allergic sensitization in Lebanese patients with allergic conjunctivitis. Int Ophthalmol 2018; 38(5):2041-51. doi: 10.1007/s10792-017-0696-y.

16. Leonardi A, Fregona IA, Gismondi M, Daniotti E, Carniel G, Secchi AG. Correlation between conjunctival provocation test (CPT) and systemic allergometric tests in allergic conjunctivitis. Eye 1990; 4:760-4. doi: 10.1038/eye. 1990.109.

17. Bonini S, Bonini S. IgE and non-IgE mechanisms in ocular allergy. Ann Allergy 1993; 71(3):296-9.

18. Rasool R, Shera IA, Nissar S, Shah ZA, Nayak N, Siddiqi MA, et al. Role of skin prick test in allergic disorders: a prospective study in kashmiri population in light of review. Indian J Dermatol 2013; 58(1):12-7. doi: 10.4103/0019-5154.105276.

19. Gelardi M, Leo ME, Quaranta VN, Iannuzzi L, Tripodi S, Quaranta $\mathrm{N}$, et al. Clinical characteristics associated with conjunctival inflammation in allergic rhinoconjunctivitis. J Allergy Clin Immunol Pract 2015; 3(3):387-91. doi: 10.1016/j.jaip. 2015.01.006.

20. Leonardi A, Piliego F, Castegnaro A, Lazzarini D, La Gloria Valerio A, Mattana P, et al. Allergic conjunctivitis: A cross-sectional study. Clin Exp Allergy 2015; 45(6):1118-1125. doi: 10.1111/cea.12536. 